\title{
Forecasting the Australian economy with DSGE and BVAR models
}

\author{
Sean Langcake ${ }^{a}$ and Tim Robinson ${ }^{b, *}$ \\ ${ }^{a}$ Economic Analysis Department, Reserve Bank of Australia. GPO Box 3947, Sydney, NSW 2001, \\ Australia. \\ ${ }^{b}$ Melbourne Institute of Applied Economic and Social Research, The University of Melbourne, VIC 3010, \\ Australia.
}

Reflecting the importance of commodities for the Australian economy, we construct a dynamic stochastic general equilibrium (DSGE) model of the Australian economy with a commodity sector. We assess whether its forecasts can be improved by using it as a prior for an empirical Bayesian vector autoregression (BVAR). We find that the forecasts from the BVAR tend to be more accurate than those from the DSGE model. Nevertheless, for output growth these forecasts do not outperform benchmark models, such as a small open economy BVAR estimated using the standard priors for forecasting. A Bayesian factor augmented vector autoregression produces the most accurate near-term inflation forecasts.

JEL Codes: E17, F47 and E37.

Keywords: Australian economy, commodities, DSGE, BVAR, forecasting.

\section{Introduction}

The rise of China and the accompanying boom and bust in commodity prices has been a major influence on the Australian economy in the past decade. In this paper we develop a multi-sector DSGE model with an explicit commodity sector to capture these effects. We assess its forecasting performance, both as a stand-alone model and by using this model as a prior for a BVAR. This may occur as DSGE models place heavy emphasis on theoretical coherence, and the high degree of structure can place tight restrictions on its parameters. These tight restrictions reduce statistical uncertainty but may impede the forecasting performance. At the other end of the spectrum, unrestricted VARs have many free parameters, and therefore can provide a better in-sample description of the data than a DSGE model. However, these parameters may be imprecisely estimated, particularly in small samples, which can reduce the VAR's forecasting performance. Using a DSGE model as a prior for a BVAR, namely estimating a BVAR-DSGE model, is a compromise between theory and data that may be useful for forecasting. ${ }^{1}$ We assess the accuracy of forecasts from both the DSGE and the BVAR-DSGE model relative to a wide range of benchmarks.

Several papers have estimated BVAR-DSGE models and evaluated their forecasting performance (see, for example, Del Negro \& Schorfheide (2004) for the United States, Hodge et al (2008) for Australia and Lees et al (2011) for New Zealand). However, the methodology used in these papers, following Del Negro \& Schorfheide (2004), does not impose the restrictions necessary to ensure that the small economy does not affect the large economy. Indeed, despite the likely importance of foreign influences for both Australia and New Zealand the latter two papers do not include observed large economy variables. Consequently, we follow the estimation approach outlined in Robinson (2013).

VAR models have been used extensively to analyse a range of issues relating to the Australian economy; here we briefly discuss some recent examples. One common research question addressed with VAR models is quantifying the influence of foreign shocks on the Australian economy. Dungey, Fry-McKibbin \& Linehan (2014), for example, examine the implications of shocks from the Chinese economy, and show that demand shocks result in long-lasting increases in commodity prices. Relatedly, Knop \& Vespignani (2014) examine the impact of commodity price shocks on the various sectors of the Australian economy. They find that the value of mining profits increase from a commodity shock, and that construction and parts of the manufacturing industry benefit from spillovers, although eventually their profits decline.

Quantifying the sectoral impacts of a range of shocks is the focus of several other Australian VAR studies. Manalo, Perera \& Rees (2015), for example, focus on exchange rate shocks, and find that the mining and manufacturing sectors are amongst the most affected. Vespignani (2013) analyses the responses to monetary

\footnotetext{
${ }^{*}$ Corresponding author. E-mail: tim.robinson@unimelb.edu.au. We thank two anonymous referees for comments which improved this paper. This research was supported by ARC DP160102654.

${ }^{1}$ For an overview of forecasting with DSGE models see Del Negro \& Schorfheide (2013).
} 
policy shocks, and concludes their largest impact is on the manufacturing and construction industries. ${ }^{2}$ From a Bayesian perspective, Voss \& Willard (2009) study the impact of U.S. monetary policy shocks on the Australian economy, and find that for both the nominal and real exchange rate Australian monetary policy shocks play a substantially larger role. Many other issues have also been addressed with VAR models; a notable example is Dungey \& Pagan (2009), which integrates insights from New-Keynesian DSGE models into the Dungey \& Pagan (2000) model of the aggregate Australian economy, as well as focusing on the implications of permanent and temporary shocks for the structure of the VAR. In contrast to these models, however, the focus of this paper is on forecasting, rather than the identification of structural shocks.

A relatively smaller literature exists on forecasting the Australian economy with either DSGE or BVAR models. ${ }^{3}$ Summers (2001) examines forecasts of the Australian economy from a BVAR containing similar variables to Dungey \& Pagan (2000) during the 1997-1998 Asian crisis and demonstrates that unlike many other forecasts the BVAR did not predict a sharp slowing in Australia's output growth, and subsequently was more accurate. Beechey \& Österholm (2008) evaluating the out-of-sample forecasting performance of a BVAR with priors on the steady-state of the variables, following Villani (2009), and find that it generally outperforms a standard BVAR. Hodge et al (2008) show that a small BVAR-DSGE model improves on the DSGE model and outperforms a Minnesota BVAR at forecasting output, but not inflation. Lees et al (2011), using the same DSGE model as a prior, finds for New Zealand that a Minnesota prior for most variables outperforms both the BVAR-DSGE and the official Reserve Bank of New Zealand forecasts. The DSGE model performs relatively poorly at forecasting inflation. Studies of DSGE-based forecasts for the Australian economy are particularly limited; unlike the literature above, Gerard \& Nimark (2008) focus on density forecasts, and in their out-of-sample based combinations of output growth, inflation and interest rate forecasts a BVAR receives the most weight, followed by a Factor-Augmented VAR (FAVAR) model, with the DSGE receiving virtually no weight.

An alternative to both BVAR and DSGE models for forecasting is to use factors, which have the advantage of incorporating a much wider range of data, and have been shown to perform well at forecasting the U.S. economy (e.g. Stock \& Watson (2002)). For Australia Tsiaplias \& Chua (2010) study several factor-based forecasts and use a BVAR as a benchmark. Their best performing factor models outperform the BVAR at forecasting inflation, but not output. Alternatively, Gillitzer \& Kearns (2007) find that factor-based forecasts can outperform autoregressive models. Recently Jiang, Athanasopoulos, Hyndman, Panagiotelis \& Vahid (2017) find that there is little advantage to using large information sets and that generally the dynamic factor models are uncompetitive with the benchmark models for forecasting both output and inflation.

The main contribution of this paper is that we evaluate the performance of an estimated DSGE model with a commodity sector and a BVAR that uses the DSGE as its prior at forecasting the Australian economy over a long evaluation period relative to numerous benchmark models. The inclusion of the commodity sector tailors the model to the Australian economy to a greater extent and the BVAR includes foreign variables which were excluded in the previous literature. We find that the BVAR-DSGE model generally improves the forecasts from the DSGE model (as measured by their root mean squared error (RMSE) and bias). However, we also find that this model does not uniformly perform better than a Minnesota BVAR and simply combining the forecasts from the models with equal weights performs well. It is most competitive at forecasting inflation, although a FAVAR model is more accurate up to one year ahead.

The rest of the paper is structured as follows. Section 2 describes the DSGE model of the Australian economy, and Section 3 its estimation and that of the BVAR-DSGE and the benchmark models. Section 4 describes the forecasting competition, and Section 5 presents the results. Finally, Section 6 concludes.

\section{The DSGE Model}

This section describes the DSGE model we use for forecasting and as the prior for the empirical BVAR. We focus on the departures from the standard small open economy model. In addition to the commodity sector and including foreign-sector variables in estimation, this model has considerably more realistic features, such as incomplete short run pass-through of exchange rate fluctuations to consumer prices, than the DSGE model used in both Hodge et al (2008) for Australia and Lees et al (2011), namely Lubik \& Schorfheide (2007).

\footnotetext{
${ }^{2}$ Brischetto \& Voss (1999) adapt the Kim \& Roubini (2000) model to Australia to study the impact of monetary policy shocks.

${ }^{3}$ An early contribution is Trevor \& Thorp (1988).
} 


\section{The domestic economy}

Incorporating the commodity sector in the model effectively introduces a second production sector. The result of this addition is that the terms of trade are exogenous, and there are sector-specific expressions for labour supply and investment. A subscript of 1 denotes the domestic good sector, and 2 the commodity sector. The complete log-linearised and steady state equations are provided in the on-line appendix.

\section{Consumers}

The representative consumer derives utility from consuming $C_{t}$ and holding real money balances $M_{t}$, and disutility from working. Hours worked are divided between the domestic and export good sectors, $L_{1, t}$ and $L_{2, t}$ respectively. We assume that these are imperfect substitutes, and therefore that wages can differ across the sectors. The consumer also derives income from renting capital to both sectors, $r_{1, t}$ and $r_{2, t}$, dividends from monopolistically competitive domestic good and import firms, $\Pi_{1, t}$ and $\Pi_{m, t}$, holdings of domestic and foreign one-period risk-free bonds, $B_{t}$ and $B_{t}^{f}$, which earn $R_{t}$ and $R_{t}^{f}$, and transfer payments, $T_{t}$. Utility is defined to be:

$$
U\left(C_{t}, L_{1, t}, L_{2, t}, M_{t}\right)=\max _{C_{t}, L_{1, t}, L_{2, t}, M_{t}} E_{0} \sum_{t=0}^{\infty} \beta^{t}\left[e^{u_{t}^{c}} \ln \left(C_{t}-v C_{t-1}\right)+\ln M_{t}-\frac{\left(L_{1, t}^{1+\xi}+L_{2, t}^{1+\xi}\right)^{\frac{1+\psi}{1+\xi}}}{1+\psi}\right]
$$

Consumers face a budget constraint, expressed in real terms as:

$$
\begin{aligned}
C_{t}+\frac{P_{1, t}}{P_{t}}\left(I_{1, t}+I_{2, t}\right)+B_{t}+S_{t} B_{t}^{f}+M_{t} & =\frac{R_{t-1} B_{t-1}}{\pi_{t}}+W_{1, t} L_{1, t}+W_{2, t} L_{2, t}+\frac{P_{1, t}}{P_{t}} r_{1, t} K_{1, t-1}+\frac{P_{2, t}}{P_{t}} r_{2, t} K_{2, t-1} \\
& +\Pi_{1, t}+\Pi_{m, t}+\frac{R_{t-1}^{f} S_{t} B_{t-1}^{f}}{\pi_{t}} \Phi\left(h_{t-1}, e^{u_{t-1}^{r p}}\right)+\frac{M_{t-1}}{\pi_{t}}+T_{t}
\end{aligned}
$$

$P_{t}$ is the price of the final consumption good and $I_{i, t}$ denotes investment. Foreign borrowing is done at a premium on domestic bond returns determined by a function $\Phi$, which depends on the level of net foreign assets as a share of GDP, $h_{t}$, and a risk premium shock $u_{t-1}^{r p} \cdot \pi_{t}$ is consumer price inflation, $S_{t}$ the nominal exchange rate (A $\$$ per unit of foreign currency), $W_{i, t}$ are real wages (deflated by consumer prices) and $K_{i, t}$ the capital stock with gross rental rate $r_{i, t} . u_{t}^{c}$ is a preference shock; $\beta$ is the discount factor; $v$ is the strength of external habits; $\psi$ is the inverse Frisch elasticity and $\xi$ governs the substitutability of labour between the sectors. ${ }^{4}$

The capital stock evolves in the same way in each sector, although depreciation rates differ. Investment adjustment costs are included, following Smets \& Wouters (2007), and there is an investment-specific technology shock that is common across sectors, which captures fluctuations in the efficiency of investment.

The consumption good is a constant elasticity of substitution (CES) aggregate of domestically produced goods from sector 1 and imports, where $\sigma$ is the elasticity of substitution between goods and $\gamma$ governs the relative importance of domestically produced goods in the consumption basket.

The first order conditions of the consumer's problem leads to a standard Euler equation and an uncovered interest rate parity condition. The non-standard features are the labour supply conditions. For example, for the domestic good sector, the labour supply equation is determined by

$$
W_{1, t}=L_{1, t}^{\xi}\left(L_{1, t}^{1+\xi}+L_{2, t}^{1+\xi}\right)^{\frac{\psi-\xi}{1+\xi}} \frac{1}{\kappa_{t}}
$$

where $\kappa_{t}$ is the Lagrange multiplier for the budget constraint.The allocation of hours worked across the sectors will depend on relative wages. The sensitivity of labour supply to wage differentials is determined by $\xi$. We also obtain sector-specifc measures for Tobin's Q; expressed in terms of consumer prices for the domestic good sector it is:

$$
q_{1, t}=\beta E_{t}\left[\frac{\kappa_{t+1}}{\kappa_{t}} \frac{\pi_{1, t+1}}{\pi_{t+1}}\left(q_{1, t+1}\left(1-\delta_{1}\right)+r_{1, t+1}\right)\right]
$$

\footnotetext{
${ }^{4}$ An expression for the evolution of nominal net foreign assets as a share of GDP, $h$, can be obtained using the budget constraint.
} 
where $\pi_{1, t}$ is inflation in the domestic good sector. The depreciation and rental rates of capital, $\delta_{i}$ and $r_{i}$, and the Euler equations are sector-specific.

\section{Domestic good sector}

Domestic good sector firms rent capital and hire labour from households, and use a Cobb-Douglas production function. $\alpha_{1}$ governs how capital intensive domestic good production is, and it is assumed to be less than the corresponding parameter in the relatively capital intensive commodity sector. There is a unit continuum of firms; for the $i$ th firm:

$$
Y_{1, t}(i)=\left(Z_{t} L_{1, t}(i)\right)^{1-\alpha_{1}} K_{1, t-1}(i)^{\alpha_{1}}
$$

where $Y_{1 t}(i)$ is output and $Z_{t}$ is labour-augmenting technology. We assume that $Z_{t}$ follows a unit root without drift, and allow for autocorrelation in its growth rate. A consequence of this is that most real variables will be cointegrated with output. The domestic good sector firm determines its demand for capital $\left(K_{1, t-1}(i)\right)$ and labour $\left(L_{1, t}(i)\right)$ by minimising real cost, deflated by the price of their output, taking $W_{1 t}$ and $r_{1 t}$ as given.

Cost minimisation by the domestic aggregator leads to a demand curve for individual goods, which the producers take as given. The domestic good sector is imperfectly competitive, and there is stickiness in prices, generated by Calvo pricing, which yields New-Keynesian Phillips curve for $\pi_{1, t}{ }^{5}$

\section{Commodity sector}

The model for the export sector draws on Dib (2008); a similar approach is also adopted in Rees, Smith \& Hall (2016). It is perfectly competitive, and takes commodity prices in foreign currency, $P_{2, t}^{*}$, as given. Consequently, in domestic currency are $P_{2, t}=S_{t} P_{2, t}^{*}$. The world price is distinct from foreign consumer prices, $P_{t}^{*}$. The exporter's problem in real terms is:

$$
\begin{aligned}
& \max _{L_{2, t}, K_{2, t-1}}\left(\frac{S_{t} P_{2, t}^{*}}{P_{t}} Y_{2 t}-W_{2, t} L_{2, t}-\frac{S_{t} P_{2, t}^{*}}{P_{t}} r_{2, t} K_{2, t-1}\right) \\
& \text { s.t. } Y_{2, t}=A_{2, t}\left(Z_{t} L_{2, t}\right)^{1-\alpha_{2}}\left(K_{2, t-1}\right)^{\alpha_{2}}
\end{aligned}
$$

where $A_{2, t}$ is an export-specific technology shock.

\section{Importing firms}

The importing sector is standard and follows Monacelli (2005). The law-of-one-price is assumed to hold at the docks, which are marked up by the monopolistically retail sector, which yields a New-Keynesian Phillips curve for import prices.

\section{Monetary policy}

The central bank sets the policy rate using a Taylor rule of inflation and value-added output, $v a_{t}$, as well as growth in value-added output ( denotes log-deviations from steady state). ${ }^{6}$ :

$$
\widetilde{R}_{t}=\zeta^{R} \widetilde{R}_{t-1}+\zeta^{R}\left(\zeta^{\pi} \widetilde{\pi}_{t}+\zeta^{v a} \widetilde{v a}_{t}+\zeta^{g r}\left(\widetilde{v a}_{t}-\widetilde{v a}_{t-1}\right)\right)+\epsilon_{t}
$$

\section{Market-clearing conditions}

Apart from factor markets, the market-clearing conditions for the $i$ th domestic good firm is that its output equals that demanded by the aggregator. Identical conditions hold for importers. The market-clearing condition for the domestic good aggregator is:

$$
Y_{1, t}=C_{t}^{d}+I_{1, t}+I_{2, t}
$$

Domestic bonds are in zero net supply.

\footnotetext{
${ }^{5}$ We allow for rule-of-thumb pricing, following Galí \& Gertler (1999), and include a mark-up shock.

${ }^{6}$ Value added is defined as $V A_{t} \equiv Y_{1, t}+\frac{\bar{P}_{2}}{\bar{P}_{1}} Y_{2, t}$
} 


\title{
III. Estimating the Models
}

\author{
Estimating the DSGE model
}

We estimate the DSGE model outlined above in two stages. The first stage is to estimate a BVAR model of the foreign sector with Minnesota priors using aggregates of foreign variables. This is a legitimate strategy if it is assumed that the foreign economy is predetermined and exogenous to the small economy (Jääskelä \& Nimark 2011). Second, we take the results from this BVAR model to calibrate the foreign sector in the DSGE model, and estimate the domestic parameters.

\section{Estimating the large economy Minnesota VAR}

We estimate a BVAR for the foreign sector closely following Kadiyala \& Karlsson (1997), using: the detrended level of output of Australia's trading partners; trade-weighted inflation; a G7 PPP-weighted interest rate, and, the detrended level of the terms of trade. We use broad aggregates for output and inflation in an attempt to capture the increasing importance of China, which is of particular relevance for Australia given its influence on commodity prices. Further details about the data are given in the on-line appendix. ${ }^{7}$

We use a Minnesota prior, which is commonly used in forecasting. ${ }^{8}$ The parameters in each equation are assumed to follow a multivariate normal distribution. We estimate first- and higher-order autoregressive processes for each series, over the pre-sample 1982:Q3-1992:Q4, and based on these we set the prior on the own first lag parameter to be 0.7 and 0.4 for output and inflation, and 0.8 for the interest rate and the terms of trade. The mean of the prior for all other coefficients is set to zero.

The variance of the prior is governed by two parameters, $\vartheta_{1}$ and $\vartheta_{2}$, for coefficients on own lags and other coefficients respectively. The variance of the prior for the coefficient on the $j$ th variable in the $i$ th equation of the large economy VAR, where underbars denote that the parameters are priors, is set following Kadiyala \& Karlsson (1997) as:

$$
\operatorname{Var}\left(\underline{\gamma_{i j}}\right)=\left\{\begin{array}{cc}
\frac{\vartheta_{1}}{k} & \text { for own lags } \\
\frac{\vartheta_{2} \sigma_{i}^{2}}{k \sigma_{j}^{2}} & \text { for lags of variable } j \neq i
\end{array}\right.
$$

where $k$ is the lag length and $\sigma_{i}$ is the standard error from an autoregression of the same order as the VAR for the $i$ th variable. To select $\vartheta_{1}$ and $\vartheta_{2}$, we examine the forecasting performance of the model over the pre-sample period 1989:Q4-1992:Q4. We select $\vartheta_{1}=0.01$ and $\vartheta_{2}=0.003$; if more weight is placed on the one-quarter-ahead forecasts than year-ahead forecasts, a slightly tighter prior would be chosen.

\section{DSGE calibration}

Next, we fix or calibrate the parameters of the DSGE model that enter the steady state (with one exception). The remaining parameters are estimated using Bayesian methods in Dynare.

The calibrated or fixed parameter values are shown in Table 1 . The discount factor, $\beta$, is chosen to imply a steady state annual interest rate of 3 per cent. The inverse Frisch elasticity of substitution is set to 1 , approximately the median estimated by Justiniano \& Preston (2010). The value governing the sensitivity of domestic interest rates to foreign debt is also taken from Justiniano \& Preston (2010). The elasticity of substitution between individual domestically produced and imported goods is set to imply a steady state mark-up of 25 per cent, following Cagliarini, Robinson \& Tran (2011). The elasticity of substitution between the domestic and import consumption good aggregates is set to be 0.75 , which is between the posterior estimates found by Justiniano \& Preston (2010) and Nimark (2009).

There is little literature providing estimates of $\xi=0.75$ for Australia, which governs the mobility of labour between sectors in response to real wage differentials, and as we estimate the model without using labour market data we set $\xi=0.75 .{ }^{9}$ The depreciation rates are chosen with reference to annual national accounts data, which suggest that the depreciation rate in the mining sector is lower than in the rest of the economy at nearly 5 per cent per annum. Capital's share of mining sector income, $\alpha_{2}$, is selected using the values reported in the experimental multifactor productivity estimates from the Australian Bureau of Statistics (ABS).

\footnotetext{
${ }^{7}$ The data are not real time. The detrending was done with a Hodrick-Prescott filter with $\lambda=1600$.

${ }^{8}$ For an overview of BVAR models see Wozniak (2016).

${ }^{9}$ Drawing on the estimates of Iacoviello \& Neri (2010) for the United States.
} 
Table 1: Calibrated Parameters

\begin{tabular}{llc}
\hline Coefficient & Description & Value \\
\hline$\beta$ & Discount factor & 0.9925 \\
$\psi$ & Inverse Frisch elasticity & 1 \\
$\chi$ & Interest debt sensitivity & 0.01 \\
$\gamma$ & Weight on domestic good in consumption & 0.6614 \\
$\sigma$ & Elasticity of substitution: domestic and imported goods & 0.75 \\
$\lambda^{m}$ & Elasticity of substitution: individual imported goods & 4 \\
$\lambda$ & Elasticity of substitution: individual domestic goods & 4 \\
$\xi$ & Elasticity of substitution of labour between sectors & 0.75 \\
$\delta_{1}$ & Depreciation rate, domestic goods & 0.018 \\
$\delta_{2}$ & Depreciation rate, commodity sector & 0.012 \\
$\alpha_{1}$ & Weight on capital in domestic goods production & 0.266 \\
$\alpha_{2}$ & Weight on capital in commodity production & 0.77 \\
\hline
\end{tabular}

The one parameter entering the steady-state that we estimate is $v$, the intensity of external habits. We do this as estimates in the literature vary considerably; for example, Jääskelä \& Nimark (2011) obtain a posterior mean of 0.76, whereas the median value from Justiniano \& Preston (2010) is 0.33. Consequently we set the mean of the prior to be 0.5.

Using the parameter values discussed above, and the mean of the prior for $v$, we calibrate the two remaining parameters $\gamma$, and $\alpha_{1}$ so as to match the average nominal shares of imports and investment to consumption. This yields a value of 0.66 for $\gamma_{1}$, a little below the values of around 0.8 often used in the literature (e.g. Justiniano \& Preston (2010) and Nimark (2009)). The capital intensity of the domestic good sector is considerably less than the commodity sector, and this is reflected in $\alpha_{1}$ being calibrated to 0.27 , whereas $\alpha_{2}$ is 0.77 .

\section{Data}

The observed variables used in the estimation of the DSGE model are: quarterly exports growth; investment growth; non-farm output growth; underlying inflation; the cash rate the change in the real tradeweighted exchange rate. Together with those used for the large economy VAR, these are the data used to estimate the BVARX. Details of the data sources are given in the on-line appendix. All series are demeaned before estimation.

\section{DSGE posterior}

We used random-walk Metropolis-Hastings chains with 600000 observations to find the posterior densities, shown in Table 2, dropping the first two-thirds of these observations as burn in. The sample is 1993:Q12016:Q2. ${ }^{10}$

There are several aspects of the posterior estimates to note. First, the mean Calvo parameter for domestically produced goods is high, and therefore implies a flat Phillips curve. Consequently, monetary policy shocks, while having substantial real effects, have only a small impact on inflation. A flat Phillips curve is also found for import prices. The estimates of the indexation parameters do not differ considerably from their priors. ${ }^{11}$

Turning to the Taylor rule, policy is estimated to be less aggressive towards inflation than was found by Justiniano \& Preston (2010), whereas it is more responsive to the deviation of the level of output from its steady state rather than to output growth. ${ }^{12}$ A one standard deviation quarterly monetary policy shock is around 8 basis points. Finally, the mean adjustment cost parameter for investment is lower than our prior. ${ }^{13}$

\footnotetext{
${ }^{10}$ The average acceptance rate was 37.75 per cent. A second chain was run to check for convergence.

${ }^{11}$ There is little change in the remaining parameters if these indexation parameters instead are calibrated.

${ }^{12}$ This could reflect that we have allowed technology to be non-stationary, whereas they linearly detrend observed output.

${ }^{13}$ We experimented with allowing a separate adjustment cost parameters for the export sector, but this appeared to be difficult to identify.
} 
Table 2: DSGE Estimation Results

\begin{tabular}{|c|c|c|c|c|c|c|}
\hline \multirow[t]{2}{*}{ Coefficient } & \multirow[t]{2}{*}{ Description } & \multicolumn{3}{|c|}{ Prior } & \multicolumn{2}{|c|}{ Posterior } \\
\hline & & Density & Mean & Std dev & Mean & $90 \% \mathrm{HPD}$ \\
\hline$\theta_{1}$ & Calvo domestic prices & $\mathrm{B}$ & 0.75 & 0.1 & 0.96 & $0.95-0.98$ \\
\hline$\omega_{1}$ & Indexation, domestic & B & 0.3 & 0.05 & 0.32 & $0.24-0.41$ \\
\hline$\zeta_{R}$ & Taylor rule, smoothing & B & 0.5 & 0.1 & 0.84 & $0.80-0.88$ \\
\hline$\zeta^{\pi}$ & Taylor rule, inflation & $\mathrm{N}$ & 1.5 & 0.1 & 1.46 & $1.30-1.63$ \\
\hline$\zeta^{v a}$ & Taylor rule, output & B & 0.5 & 0.2 & 0.79 & $0.64-0.95$ \\
\hline$\zeta_{d y}$ & Taylor rule, growth & B & 0.5 & 0.2 & 0.14 & $0.02-0.26$ \\
\hline$\theta_{m}$ & Calvo import & B & 0.75 & 0.1 & 0.96 & $0.95-0.99$ \\
\hline$\omega_{m}$ & Indexation, imports & B & 0.3 & 0.05 & 0.32 & $0.23-0.41$ \\
\hline$\rho_{a}$ & Technology growth & B & 0.5 & 0.2 & 0.34 & $0.13-0.54$ \\
\hline$\rho_{r p}$ & Risk premium & B & 0.75 & 0.1 & 0.91 & $0.87-0.96$ \\
\hline$\rho_{i}$ & Investment technology & B & 0.75 & 0.1 & 0.56 & $0.47-0.65$ \\
\hline$\rho_{a, 2}$ & Export technology & B & 0.75 & 0.1 & 0.88 & $0.84-0.92$ \\
\hline$\rho_{g}$ & Preferences & B & 0.75 & 0.1 & 0.86 & $0.80-0.91$ \\
\hline$\eta^{\prime \prime}$ & Adjustment costs & $\mathrm{N}$ & 4 & 0.5 & 2.77 & $1.86-3.72$ \\
\hline$v$ & Habits & B & 0.5 & 0.1 & 0.21 & $0.13-0.28$ \\
\hline \multicolumn{7}{|c|}{ Standard deviations } \\
\hline$\sigma_{r p}$ & Risk premium & $\mathrm{IG}$ & 1 & 1 & 0.50 & $0.33-0.67$ \\
\hline$\sigma_{M}$ & Monetary policy & IG & 0.25 & 0.1 & 0.09 & $0.08-0.10$ \\
\hline$\sigma_{a}$ & Technology & IG & 1 & 1 & 0.40 & $0.30-0.50$ \\
\hline$\sigma_{2}$ & Export technology & IG & 2 & 1 & 2.15 & $1.89-2.40$ \\
\hline$\sigma_{i}$ & Investment technology & IG & 5 & 1 & 11.37 & $7.66-14.96$ \\
\hline$\sigma_{c}$ & Preferences & $\mathrm{IG}$ & 1 & 1 & 2.80 & $2.16-3.40$ \\
\hline$\sigma_{1}$ & Domestic mark-up & IG & 0.5 & 1 & 0.17 & $0.13-0.21$ \\
\hline$\sigma_{m}$ & Imports mark-up & IG & 0.5 & 1 & 0.24 & $0.16-0.32$ \\
\hline
\end{tabular}

Notes: Prior distributions are B - Beta, N - Normal, IG - inverse Gamma;

HPD denotes highest probability density; foreign sector estimates are excluded.

\section{Estimating the BVAR}

We now turn to the BVAR model that we wish to use for forecasting. The large economy variables are included as exogenous variables in the equations for the small open economy. This specification allows forecasts for the large economy from professional forecasters to potentially be utilised, such as those in the International Monetary Fund's (IMF) World Economic Outlook, although here we use forecasts from the large economy Minnesota VAR described previously. The specification of the BVAR is:

$$
y_{t}=\sum_{i=1}^{p} \Phi_{i} y_{t-i}+\alpha \beta^{\prime} y_{t-1}^{n s}+\sum_{j=0}^{q} \Phi_{j}^{x} x_{t-j}+u_{t}, u_{t} \sim N\left(0, \Sigma_{u}\right),
$$

where $y_{t}$ is a vector of $n$ small economy variables that can be split into two components, namely $\Delta y_{t}^{n s}$ which are the first difference of variables that according to the DSGE model are non-stationary, and $y_{t}^{s}$, which are stationary. $\Phi_{i}$ are coefficients on lags of $y_{t}, \Phi_{j}^{x}$ are the coefficients on the contemporaneous terms and lags of $x_{t}$, which is a vector of the large economy variables, and $u_{t}$ are the shocks, which are normally distributed with variance-covariance matrix $\Sigma_{u} \cdot{ }^{14}$ Because the DSGE model contains a permanent technology shock, it predicts cointegration among the non-stationary observed variables, and consequently we estimate a vector error correction model, where $\beta$ is the cointegrating vector (we impose the values implied by the DSGE model) and $\alpha$ are the loadings on the error-correction terms. We will refer to this model as a BVECMX model. We also estimate a variant without these cointegrating terms, namely a BVARX model.

\section{The BVECMX prior}

The approach we take to construct the prior follows Robinson (2013), which itself draws on DeJong, Ingram \& Whiteman (1993). This method allows us to easily include both the large economy variables

\footnotetext{
${ }^{14}$ For simplicity we set $p=q$.
} 
that are exogenous to the small economy and the error-correction terms, as described above. In brief, by repeatedly drawing DSGE parameters from their posterior, simulating data using these parameters, and estimating a VAR on the simulated data, we map out what the DSGE posterior implies for the BVECMX parameters and the variance-covariance matrix of the shocks. We then use these estimates to inform our selection of the parameters of the prior. ${ }^{15}$ We assume that the parameters are distributed according to the independent Normal-Wishart prior described by Koop \& Korobilis (2010), and restrict the parameter space to where the VAR is stable. ${ }^{16}$ Finally, one way of relaxing the prior on the BVECMX parameters is to scale up its variance-covariance matrix by a factor of $\lambda$, which implies that the prior is given less weight. ${ }^{17}$

\section{The BVECMX posterior}

The posterior of the BVECMX parameters is obtained using Gibbs sampling. The conditional densities are the standard for the Inverted-Wishart Normal prior; details are available in Robinson (2013) or Koop \& Korobilis (2010). ${ }^{18}$

\section{Estimating the benchmark models}

Six benchmark models are used to produce comparison forecasts to the BVECMX and the DSGE model: a small open economy (SOE) Minnesota VAR; a SOE Minnesota Factor Augmented VAR (FAVAR); an unrestricted VAR and separate univariate $\mathrm{AR}(2)$ models for each observed variable. The unrestricted VAR is estimated using equation-by-equation Ordinary Least Squares and the univariate autoregressive models by maximum likelihood. The final two benchmark models are two combinations of the point forecasts of the models, namely (1) the DSGE model and the SOE Minnesota VAR, and (2) the DSGE, SOE Minnesota and the FAVAR. We use equal weights, which have been found in the literature to perform well (see, for example, Clemen (1989)).

\section{The small open economy Minnesota VAR}

In the SOE Minnesota VAR, the large economy variables are included in the vector of endogenous variables and block exogeneity is imposed. Unlike the large economy Minnesota VAR used as a prior for the BVECMX, we do not treat the variance-covariance matrix of the shocks as fixed; instead, we use the variant of the independent Normal-Wishart prior described above. Consequently, the SOE Minnesota VAR is a natural benchmark for the BVECMX model. As this Minnesota VAR includes the large economy variables it is a tougher benchmark than the Minnesota VARs used by Hodge, Robinson \& Stuart (2008) and Lees, Matheson \& Smith (2011).

The main way the SOE Minnesota VAR differs from the BVECMX model is in the parameters of the prior. For the large economy equations, the priors are the same and block exogeneity is imposed. For the small economy equations we estimate first-order and higher-order autoregressive models, as was done for the large economy Minnesota VAR above, with the longest pre-sample used being 1982:Q3-1992:Q4. The mean of the prior for the coefficients are: exports 0 ; investment 0 ; output 0.3 ; inflation 0.6 ; interest rates 0.7 , and real exchange rate $0 .{ }^{19}$

The remaining parameters of the prior for the SOE Minnesota VAR are $\vartheta_{1}$ and $\vartheta_{2}$, which determine the standard deviations of the prior on the coefficients on lags of the own variable and other variables. As for the large economy Minnesota VAR, to choose these we examined the performance of a Minnesota VAR in forecasting the Australian variables over a pre-sample period 1989:Q4-1992:Q4. ${ }^{20}$ We set $\vartheta_{1}=0.07$; there appeared to be a trade-off between the one-quarter-ahead (which would suggest a smaller value for $\vartheta_{1}$ ) and the year-ahead forecasts. The forecasting exercise suggested a very small value of $\vartheta_{2}$, which would effectively reduce the VAR to a collection of univariate autoregressive processes. Consequently we set $\vartheta_{2}=0.005$, which Kadiyala \& Karlsson (1997) describe as a standard value. We construct the prior for the variance-covariance

\footnotetext{
${ }^{15}$ As we are drawing from the posterior of the DSGE this is an empirical Bayesian approach. For an overview of empirical Bayes analysis see Casella (1985).

${ }^{16}$ This places a multivariate normal prior over the (vectorised) parameters of the VAR, and a Wishart prior over the inverse of the variance-covariance matrix of the reduced-form shocks. We set the degrees of freedom parameter in the latter to be $n+2$.

${ }^{17} \mathrm{As}$ the number of parameters in the BVECMX is greater than that in the DSGE, to ensure that the prior for the variancecovariance matrix of the parameters is non-singular we add a small amount (0.01) to the standard deviation for all parameters after any scaling by $\lambda$.

${ }^{18}$ We simulate 31000 observations, dropping the first 1000 . The stability condition is implemented by dropping all unstable draws.

${ }^{19}$ For investment, the sample was 1986:Q1 onwards due to data availability.

${ }^{20}$ We use the Minnesota prior to save computational time, and exclude business investment due to data availability.
} 
matrix of the shocks so that the mean coincides with that of the Minnesota prior, following Kadiyala and Karlsson. ${ }^{21}$

\section{The small open economy Minnesota FAVAR}

The FAVAR model represents a different benchmark to the other models in that it incorporates information from a wide variety of series, beyond those used to estimate either the BVECMX or the DSGE model. Consequently, the FAVAR is likely to be a relatively tough benchmark. The model is also estimated using Bayesian methods, motivated by the potential improvement in forecasting performance from shrinking the parameters.

The additional information included in the FAVAR model is summarised in two factors, which we estimate with principal components. The data included in the factors are from both official (Australian Bureau of Statistics) and unofficial sources, and cover many aspects of the economy. The choice of series included, which are shown in Table 3, was guided partially by Gillitzer \& Kearns (2007), which demonstrated that using factors can improve the accuracy of forecasts of the Australian economy, and those included in the Westpac-Melbourne Institute Leading Index of Economic Activity. In all, 31 series were used; this is less than by Jiang et al. (2017), although they use only official and Reserve Bank of Australia data. All series were transformed so as to be stationary and normalized. We augment the data with lags of itself, as in Stock \& Watson (2002); we use two lags. The first two factors account for around 31 per cent of the total variation in the data.

Table 3: FAVAR Data

\begin{tabular}{lc}
\hline Data & Transformation \\
\hline Hours worked, ms & $\mathrm{D}$ \\
Labour productivity, hours, ms, index & $\mathrm{D}$ \\
Household consumption, cv & $\mathrm{D}$ \\
Government consumption, cv & $\mathrm{D}$ \\
Government investment, cv & $\mathrm{D}$ \\
Domestic final demand, cv & $\mathrm{D}$ \\
Residential Investment, cv & $\mathrm{D}$ \\
Imports, cv & $\mathrm{D}$ \\
Compensation of employees & $\mathrm{D}$ \\
Gross mixed income & $\mathrm{D}$ \\
Gross operating surplus & $\mathrm{D}$ \\
Real non-farm unit labour costs & $\mathrm{L}$ \\
GDP deflator & $\mathrm{D}$ \\
Import deflator & $\mathrm{D}$ \\
Consumer Sentiment Current Conditions Index & $\mathrm{L}$ \\
Consumer Sentiment Expectations Index & $\mathrm{L}$ \\
Dwelling Approvals, number & $\mathrm{D}$ \\
Employment & $\mathrm{D}$ \\
Housing Finance Approvals, number & $\mathrm{D}$ \\
Housing Finance Approvals, value & $\mathrm{D}$ \\
Non-residential Building Approvals, value & $\mathrm{D}$ \\
Participation rate & $\mathrm{N}$ \\
S\&P ASX 200 & $\mathrm{D}$ \\
Unemployment & $\mathrm{D}$ \\
Unemployment rate & $\mathrm{N}$ \\
Employment to population ratio & $\mathrm{N}$ \\
Unemployment Expectations Index & $\mathrm{L}$ \\
Change in real inventories & $\mathrm{N}$ \\
Yield spread & $\mathrm{N}$ \\
Private Business Investment, cv & $\mathrm{D}$ \\
Exports, cv & $\mathrm{D}$ \\
\hline Notes: cv - chain volume; ms - market sector; L log level; \\
D - first difference of logs; N - no transformation. & \\
& \\
\hline
\end{tabular}

${ }^{21}$ As before, we set the degrees of freedom parameter in the Wishart distribution to be $n+2$. 
We include these two factors in a small open economy Minnesota VAR, using the same prior as above. Pre-sample estimates suggest that the factors are persistent, and consequently the mean of the prior for their coefficients were set to 0.9 and 0.8 respectively. As the resulting VAR is large, we omit exports and investment growth, but instead include them in the factors.

\section{Forecasting}

\section{Methodology}

The forecasting process for the BVECMX is as follows. Given a draw from the posterior, a vector of shocks is drawn and is used to generate a forecast of $y_{t+1}$. We then iterate forward, using the same parameters and repeatedly draw new shocks, to obtain the forecasts at longer horizons. This is repeated 1000 times, to generate the forecast density, from which we calculate a mean forecast. As we have demeaned the variables prior to estimation, we add back the mean of the data to obtain the final forecasts.

The BVECMX model requires forecasts of the exogenous variables, namely those of the large economy. As discussed above, these are generated using the large economy Minnesota VAR. ${ }^{22}$

\section{Evaluation}

To evaluate the forecast performance of the various models we recursively construct out-of-sample forecasts for the period 2006:Q1-2016:Q2, that is, for each quarter, we re-estimate the models before forecasting. ${ }^{23}$ We focus on the quarterly forecasts one and two quarters ahead, as well as the year-ended forecasts one and two years ahead, for all variables except the interest rate. We compare the forecasting performance across models primarily by their RMSE and their bias; Mean Absolute Errors are reported in the on-line appendix. ${ }^{24}$

\section{Results}

Table 4 shows the performance of the BVECMX relative to the DSGE and our six benchmark models.

The unrestricted VAR is not an useful forecasting tool. At all horizons and for all variables, with the exception of investment, it is outperformed by the BVECMX model. For example, the RMSE of the BVECMX relative to the unrestricted VAR for output growth one-quarter ahead is 0.75 . This results is not surprising, as the unrestricted VAR contains many parameters which may be imprecisely estimated in a small sample. Addressing this is a motivation for adopting Bayesian techniques, and it is apparent from Table 4 that any of the models using it outperform the unrestricted VAR.

The BVECMX generally improves the forecasts of the DSGE model, with the exception of one-quarter ahead output and investment forecasts and the interest rate forecasts at longer horizons. This result is broadly in line with the findings of Hodge et al. (2008) and Lees et al. (2011). ${ }^{25}$ It has been argued that BVARs with Minnesota priors forecast well (see, for example, Litterman (1986)). In this case, the SOE Minnesota VAR also generally outperforms the DSGE model with the the exception of the interest rate, although at long horizons the DSGE model also is more accurate for inflation and exports. The out-performance of the SOE Minnesota VAR is largest for output. Overall, the results for the DSGE model are less positive than those found for the US by Smets \& Wouters (2007). One possibility is that the fit and/or forecasting performance of DSGE models might generally be better for relatively closed economies, such as the United States, or it could be intrinsically more difficult to forecast small open economies or commodity exporters. This result aligns with the finding of Gerard \& Nimark (2008) that when combining the density forecasts of a DSGE model similar to Jääskelä \& Nimark (2011) with a BVAR and a FAVAR the DSGE received negligible weight.

\footnotetext{
${ }^{22}$ For simplicity, we use the posterior mean of the VAR parameters, rather than taking into account parameter uncertainty. Kadiyala \& Karlsson (1997) describe this as the 'customary' approach.

${ }^{23}$ The mean of the data over the estimation period is added back into the forecasts.

${ }^{24} \mathrm{~A}$ common approach is to assess whether the performance of the forecasts are statistically significant using the Diebold \& Mariano (1995) statistic. Unfortunately the Diebold-Mariano statistic is not applicable as, for example, it does not accommodate nested models. The recursive estimation sample also means that the Giacomini \& White (2006) test is not applicable. As the Australian inflation-targeting sample is short, it seemed preferable to maintain the recursive, rather than rolling, sample.

${ }^{25}$ In contrast, Kolasa, Rubaszek \& Skrzypczyński (2012) found that a modified version of Smets \& Wouters (2007) generally outperformed a BVAR-DSGE model using it as a prior.
} 
Table 4: Relative RMSEs of BVECMX Model

\begin{tabular}{|c|c|c|c|c|c|c|c|c|c|c|c|c|c|c|}
\hline Series & Minn & $\mathrm{AR}$ & VAR & DSGE & Combined & FAVAR & Combined 2 & Minn & $\mathrm{AR}$ & VAR & DSGE & Combined & FAVAR & Combined 2 \\
\hline Quarterly & \multicolumn{7}{|c|}{ 1-quarter-ahead } & \multicolumn{7}{|c|}{ 2-quarters-ahead } \\
\hline$\Delta$ Exports & 1.04 & 1.10 & 0.87 & 1.00 & 1.08 & - & - & 1.01 & 1.04 & 0.91 & 0.99 & 1.05 & - & - \\
\hline$\Delta$ Investment & 1.20 & 1.03 & 1.07 & 1.04 & 1.15 & - & - & 1.29 & 1.24 & 1.12 & 1.00 & 1.15 & - & - \\
\hline Growth & 1.12 & 1.11 & 0.75 & 1.05 & 1.10 & 1.11 & 1.11 & 1.26 & 1.21 & 0.89 & 0.98 & 1.14 & 1.19 & 1.16 \\
\hline Inflation & 1.01 & 1.04 & 0.86 & 0.96 & 1.00 & 1.06 & 1.03 & 0.96 & 0.99 & 0.92 & 0.92 & 0.96 & 1.06 & 1.00 \\
\hline Cash rate & 1.03 & 1.06 & 0.84 & 0.91 & 1.09 & 1.03 & 1.10 & 1.02 & 1.01 & 0.78 & 1.06 & 1.15 & 1.06 & 1.15 \\
\hline$\Delta \operatorname{Rer}$ & 1.03 & 1.02 & 0.84 & 0.96 & 1.07 & 1.01 & 1.08 & 0.99 & 0.98 & 0.81 & 0.97 & 1.02 & 0.97 & 1.02 \\
\hline Year-ended & \multicolumn{7}{|c|}{ 1-year-ahead } & \multicolumn{7}{|c|}{ 2-years-ahead } \\
\hline$\Delta$ Exports & 0.96 & 1.43 & 0.76 & 0.97 & 1.29 & - & - & 0.98 & 1.24 & 0.99 & 1.03 & 1.16 & - & - \\
\hline$\Delta$ Investment & 1.22 & 1.17 & 1.06 & 0.92 & 1.06 & - & - & 0.88 & 0.95 & 0.81 & 0.85 & 0.87 & - & - \\
\hline Growth & 1.40 & 1.23 & 0.93 & 0.92 & 1.14 & 1.27 & 1.19 & 1.00 & 0.91 & 0.87 & 0.81 & 0.92 & 0.98 & 0.95 \\
\hline Inflation & 0.95 & 1.00 & 0.83 & 0.95 & 0.97 & 1.11 & 1.02 & 0.95 & 0.96 & 0.87 & 0.99 & 0.98 & 0.95 & 0.97 \\
\hline Cash rate & 1.03 & 0.92 & 0.85 & 1.25 & 1.19 & 1.08 & 1.17 & 1.08 & 0.79 & 0.99 & 1.14 & 1.12 & 1.02 & 1.09 \\
\hline$\Delta$ Rer & 0.96 & 1.01 & 0.77 & 0.91 & 1.04 & 0.92 & 1.04 & 1.02 & 0.99 & 0.94 & 0.98 & 1.04 & 0.98 & 1.03 \\
\hline
\end{tabular}

Notes: Values less than 1 indicate the RSME of the BVECMX is less than the benchmark and therefore has more accurate forecasts; 1- and 2-years-ahead

interest rate forecasts are for the level; VARs have 2 lags; Minn denotes SOE Minnesota VAR; Combined combines 2 models; Combined 2 combines 3 models; AR denotes autoregressive; Rer denotes real exchange rate 
Comparing the forecasting performance of the SOE Minnesota BVAR and the BVECMX two noticeable results emerge. First, for horizons up to one-year ahead, the Minnesota prior outperforms at forecasting both output and investment growth, and sometimes by a substantial amount. Second, the BVECMX is more accurate at forecasting inflation 2 or more quarters ahead. The theory-based priors consequently seem to be most useful for forecasting inflation. This result is somewhat surprising, given that Norman \& Richards (2012) find a New Keynesian Phillips curve to be uncompetitive at forecasting with other single equation models of inflation, although numerous differences exist between our study and theirs, such as the evaluation period used and the estimation approach. ${ }^{26}$

Reflecting that shrinkage is important in improving the forecasts, the simple autoregressive models prove to be a tough benchmark. ${ }^{27}$ The SOE Minnesota VAR does tend to forecast investment more accurately, and also does so for output at horizons of two quarters or greater and the cash rate a year or further ahead. The forecasts for exports growth, however, are substantially worse. Consistent with the findings of Atkeson \& Ohanian (2001), for forecasting inflation it is difficult to beat a simple model. The FAVAR model, however, does so for all horizons except two years ahead. Given the informational advantage that the FAVAR model has it is somewhat surprising that it does not perform better than the autoregressive or SOE Minnesota VAR for output, although this aligns with the factor forecasts of Tsiaplias \& Chua (2010) and the findings of Jiang et al. (2017).

Finally, combining the forecasts from the DSGE and the SOE Minnesota VAR together with equal weights delivers forecasts that are generally more accurate than the BVECMX model, with the exception of inflation and the two-year-ahead forecasts more generally. The advantage at forecasting inflation disappears when the FAVAR model is included in the combination (the 'Combined 2' model), reflecting the FAVAR's good performance at forecasting inflation. Overall, the results suggests that combining the forecasts ex-post from the DSGE and BVAR models delivers more accurate forecasts and is computationally much simpler. It should be noted that the many previous studies, such as Hodge et al. (2008), Lees et al. (2011) and Del Negro \& Schorfheide (2004), do not include this simple benchmark. ${ }^{28}$

Another metric for evaluating the forecasts is their bias, i.e. do they over- or under-predict on average? This has not been examined in many previous studies, including Hodge et al. (2008) and Lees et al. (2011). Table 5 shows the bias in the forecasts of three of the models - the BVECMX, the DSGE and, as a benchmark, the SOE Minnesota VAR.

\begin{tabular}{|c|c|c|c|c|c|c|}
\hline \multicolumn{7}{|c|}{ Table 5: Bias } \\
\hline Variable & BVECMX & DSGE & Minn & BVECMX & DSGE & Minn \\
\hline Quarterly & \multicolumn{3}{|c|}{ 1-quarter-ahead } & \multicolumn{3}{|c|}{ 2-quarters-ahead } \\
\hline$\Delta$ Exports & 0.38 & $0.84^{*}$ & -0.35 & 0.43 & $0.79^{*}$ & -0.46 \\
\hline$\Delta$ Investment & $2.11^{*}$ & $2.13^{*}$ & $1.71^{*}$ & $2.42^{*}$ & $2.84^{*}$ & $1.58^{*}$ \\
\hline Growth & $0.26^{*}$ & $0.19^{*}$ & 0.12 & $0.29 *$ & $0.29 *$ & 0.10 \\
\hline Inflation & -0.02 & -0.03 & -0.01 & -0.02 & -0.02 & -0.01 \\
\hline Cash rate & 0.14 & -0.07 & $0.15^{*}$ & $0.36^{*}$ & -0.06 & $0.35^{*}$ \\
\hline$\Delta \operatorname{Rer}$ & 0.04 & $-1.92^{*}$ & 1.31 & 0.09 & -1.64 & 0.80 \\
\hline Year-ended & \multicolumn{3}{|c|}{ 1-year-ahead } & \multicolumn{3}{|c|}{ 2-years-ahead } \\
\hline$\Delta$ Exports & 1.75 & $3.04^{*}$ & -1.68 & 1.07 & $1.76^{*}$ & -1.40 \\
\hline$\Delta$ Investment & $7.53^{*}$ & $9.97^{*}$ & $6.72^{*}$ & 5.93 & $9.28^{*}$ & $7.87^{*}$ \\
\hline Growth & $1.05^{*}$ & $1.13^{*}$ & 0.50 & $0.98^{*}$ & $1.23^{*}$ & $0.80^{*}$ \\
\hline Inflation & -0.11 & -0.10 & -0.06 & -0.20 & -0.01 & -0.12 \\
\hline Cash rate & $0.86^{*}$ & 0.21 & $0.74^{*}$ & $1.44^{*}$ & $1.04^{*}$ & $1.22^{*}$ \\
\hline$\Delta$ Rer & 0.33 & $-6.09 *$ & 2.92 & 0.55 & -2.25 & 2.87 \\
\hline
\end{tabular}

\footnotetext{
${ }^{26}$ Abbas, Bhattacharya, Mallick \& Sgro (2016) also are critical of the New Keynesian Phillips curve as a model of inflation for Australia, although they focus on evaluating variants of the curve in Gali \& Monacelli (2005), rather than the approach in this model which allows for incomplete short-run pass through in import prices, which is a common specification in empirical small-open economy DSGE models.

${ }^{27}$ This is not an uncommon result; for example, it was also found by Beechey \& Österholm (2008) and Jiang et al. (2017).

${ }^{28}$ Ghent (2009) examines forecast combination, but of BVAR-DSGE models with different DSGEs (real business cycle and sticky price) used to generate the prior. Little improvement is found from combining these models.
} 
Several implications emerge from Table 5. First, looking across the variables, the investment forecasts tend to be biased, regardless of the model used. Over the first half of the evaluation period there was an investment boom in the mining sector, in response to the high commodity prices and the terms of trade, which subsequently unwound. It appears that all of the models have difficulties capturing these dynamics, despite the DSGE model having an explicit commodity sector. Relatedly, export growth tends be over predicted by both the DSGE model and the BVECMX model, although only significantly so in the former. This may reflect that during the investment boom in the mining sector there was not a commensurate increase in export growth, and consequently measured productivity in the mining sector declined. Interestingly, the SOE Minnesota VAR instead under predicted exports growth, but not to a significant extent.

The terms of trade boom from around 2003 onwards was not predicted by many forecasters, including the RBA (see Kearns \& Lowe (2011)), and the pace of its decline also surprised forecasters. Given these developments, and the fact that movements in the terms of trade and the real exchange rate are typically quite correlated, it is somewhat surprising that the bias in the forecasts for the change in the real exchange rate generally are quite small (with the exception of the DSGE model).

Output growth is over-predicted on average by all models. The demeaning of the data probably contributes to this bias. At the beginning of the sample there was strong growth as the economy emerged from the early 1990s recession, whereas for much of the 2000s productivity growth was weak, with the commodities boom one likely contributing factor. ${ }^{29}$ As a result, the growth rate to which our forecasts are assumed to revert may be too high, even though we have allowed economy-wide technology to be non-stationary.

The bias in the inflation forecasts in the near-term from all of the models is slight, and increases only slightly at longer horizons.

Looking across the models, the bias in the forecasts tends to be largest for the DSGE model. It appears that one advantage of using the DSGE model as a prior is that the bias tends to be moderated, with the notable exception of the cash rate at longer horizons. The bias, however, generally is smaller for the SOE Minnesota VAR, except for the change in the real exchange rate.

\section{Sensitivity analysis}

Reflecting that the BVAR tended to improve the forecasts of the DSGE model, we focus on the implications of variations to the BVECMX model.

\section{Excluding the error-correction terms}

The implications of excluding the error-correction terms for the BVECMX (which we term BVARX) are shown in Table 6. It appears that including the error-correction terms has a mixed impact on the forecast accuracy. For example, at most horizons the accuracy of exports and investment forecasts tends to be reduced by their inclusion. This is not that surprising as the DSGE model implies specific values for the cointegrating vectors which may differ from those evident in the data (for further details see Dungey \& Pagan (2009)). At the short horizons there is little impact on the growth forecasts, whereas at longer horizons it has an adverse impact, but improves the inflation and particularly the interest rate forecasts.

${ }^{29}$ For one discussion of trends in Australian productivity over the 2000s see Eslake (2011). 
Table 6: BVECMX and BVARX Forecast Results - RMSE

\begin{tabular}{|c|c|c|c|c|}
\hline Series & \multicolumn{2}{|c|}{ Including EC terms } & \multicolumn{2}{|c|}{ Excluding EC terms } \\
\hline Quarterly & 1-quarter & 2-quarters & 1-quarter & 2-quarters \\
\hline$\Delta$ Exports & 2.19 & 2.22 & 2.03 & 2.10 \\
\hline$\Delta$ Investment & 4.77 & 5.09 & 4.59 & 4.88 \\
\hline Growth & 0.55 & 0.58 & 0.53 & 0.57 \\
\hline Inflation & 0.20 & 0.21 & 0.20 & 0.21 \\
\hline Interest rates & 0.37 & 0.80 & 0.38 & 0.80 \\
\hline$\Delta$ rer & 5.06 & 5.02 & 5.05 & 4.97 \\
\hline Year-ended & 1-year & 2-years & 1-year & 2-years \\
\hline$\Delta$ Exports & 3.82 & 2.51 & 3.53 & 2.89 \\
\hline$\Delta$ Investment & 14.08 & 13.76 & 11.57 & 12.57 \\
\hline Growth & 1.54 & 1.53 & 1.19 & 1.33 \\
\hline Inflation & 0.69 & 0.67 & 0.79 & 0.78 \\
\hline Interest rates & 1.50 & 1.46 & 1.95 & 1.90 \\
\hline$\Delta$ rer & 10.92 & 10.59 & 10.69 & 10.58 \\
\hline
\end{tabular}

\section{Prior sensitivity}

The forecasting performance of the BVECMX is relatively insensitive to the looseness of the prior, governed by the parameter $\lambda$ (Table 7). For some variables, such as inflation, the forecasts made using different values of $\lambda$ are highly correlated, which probably reflects the persistence in these variables. Loosening the prior, generally leads to a small deterioration of accuracy of the output growth and inflation forecasts, whereas the near-term interest rate and real exchange rate forecasts improve. Focusing on the output growth and inflation forecasts, overall it appears that a tight prior with $\lambda=1$ is preferable.

Table 7. BVECMX Forecast Results - RMSE

\begin{tabular}{|c|c|c|c|c|c|c|c|c|}
\hline & & & & & & & & \\
\hline Series & 1 & 10 & 50 & 100 & 1 & 10 & 50 & 100 \\
\hline Quarterly & \multicolumn{4}{|c|}{ 1-quarter } & \multicolumn{4}{|c|}{ 2-quarters } \\
\hline$\Delta$ Exports & 2.19 & 2.22 & 2.28 & 2.24 & 2.22 & 2.24 & 2.22 & 2.23 \\
\hline$\Delta$ Investment & 4.77 & 5.20 & 5.23 & 5.09 & 5.09 & 5.14 & 4.90 & 4.74 \\
\hline Growth & 0.55 & 0.59 & 0.59 & 0.58 & 0.58 & 0.59 & 0.57 & 0.56 \\
\hline Inflation & 0.20 & 0.20 & 0.21 & 0.21 & 0.21 & 0.22 & 0.22 & 0.22 \\
\hline Interest rates & 0.37 & 0.36 & 0.36 & 0.35 & 0.80 & 0.79 & 0.79 & 0.79 \\
\hline$\Delta$ rer & 5.06 & 5.04 & 5.02 & 5.02 & 5.02 & 5.03 & 4.98 & 4.97 \\
\hline Year-ended & \multicolumn{4}{|c|}{ 1-year } & \multicolumn{4}{|c|}{ 2-years ahead } \\
\hline$\Delta$ Exports & 3.82 & 3.90 & 3.90 & 3.89 & 3.53 & 3.59 & 3.52 & 3.55 \\
\hline$\Delta$ Investment & 14.08 & 14.44 & 13.91 & 13.45 & 11.57 & 11.53 & 11.77 & 11.71 \\
\hline Growth & 1.54 & 1.61 & 1.58 & 1.55 & 1.19 & 1.23 & 1.28 & 1.30 \\
\hline Inflation & 0.69 & 0.71 & 0.73 & 0.74 & 0.79 & 0.79 & 0.80 & 0.82 \\
\hline Interest rates & 1.50 & 1.52 & 1.54 & 1.55 & 1.95 & 1.99 & 2.07 & 2.10 \\
\hline$\Delta$ rer & 10.92 & 10.63 & 10.59 & 10.67 & 10.69 & 10.70 & 10.66 & 10.71 \\
\hline
\end{tabular}




\section{Extending the estimation period}

The estimation sample used was the inflation-targeting period (1993:Q1 onwards). Hence, the models for the early samples in the forecasting exercise were estimated with only a small amount of data, which may make the use of a relatively tight prior for the VAR preferable. To test the importance of sample size, we re-estimate the BVARX over a longer sample (1986:Q2 onwards). ${ }^{30}$ The most notable difference is that the BVARX forecasts inflation and investment more accurately when the longer sample is used, whereas the forecasts for the interest rate deteriorate. The latter is not surprising given that the estimation sample now includes multiple monetary policy regimes. This pattern, however, is not isolated to the BVARX; for example, it is also observed for the $\operatorname{AR}(2)$ models. Relative to these models, using the longer sample the BVARX forecasts inflation and interest rates more accurately, but output less so (see the on-line appendix).

\section{The global financial crisis}

A major economic event during our forecast evaluation period is the global financial crisis. While Australia did not have a recession during the financial crisis, it is interesting to consider the performance of the DSGE and the BVECMX models around this time. Examining the forecasts, it is apparent that from either model the early forecasts for the crisis period were for around, or slightly above, trend growth. Throughout the first half of 2008, the mean one-quarter-ahead forecasts were generally revised lower for the BVECMX, reflecting the soft growth outcomes which occurred, with only small revisions to to the forecasts from the DSGE model. Neither model anticipated the sharp drop in output that occurred in the December quarter of 2008; indeed, none of the models considered forecast output growth well over this period.

One possible explanation as to why the mean forecasts from these models missed the extent of the impact of the global financial crisis is that they do not contain enough financial variables, for example, credit aggregates and interest-rate spreads are not included in the model. Developing this aspect of these models is currently a very active area of research. Edge \& Gürkaynak (2010) review the forecasting performance for the United States economy of the Smets \& Wouters (2007) model, a Minnesota VAR in the observable variables of the DSGE and the Blue Chip monthly survey of business economists. They found that '[a]lthough all the forecasts clearly first miss the [United States'] recession, and then miss its severity, the Blue Chip forecasts in general fare better as the quarter to be forecasted gets closer, and especially when nowcasting' (p 235). This improved performance is likely to be partially due to the fact that the analysts included in the Blue Chip forecasts can utilise additional timely information in constructing their forecasts. Del Negro \& Schorfheide (2013) find that augmenting the Smets \& Wouters (2007) model with a financial accelerator mechanism, following Bernanke, Gertler \& Gilchrist (1999), and using spreads as an observed variable, yield forecasts during the financial crisis that are more accurate and become "competitive" with the Blue Chip Survey. Del Negro, Hasegawa \& Schorfheide (2016), however, demonstrate that outside crisis periods the inclusion of the financial friction lessens the accuracy of the forecasts. ${ }^{31}$ The forecasting accuracy of variants of a small open-economy model of Sweden with a financial accelerator mechanism are examined by Christiano, Trabandt \& Walentin (2011). The inflation and interest rate forecasts are found to improve relative to the baseline DSGE model, although the one and four-quarter-ahead forecasts of output growth deteriorate.

The financial crisis was essentially an external shock for Australia, and therefore introducing the standard financial accelerator mechanism which links the external finance premium to the net worth of domestic entrepreneurs seems unlikely to substantially improve the forecasts for that period. More generally, the type of financial frictions likely to be of particular relevance to Australia are housing related. Ng \& Feng (2016) and Christensen, Corrigan, Mendicino \& Nishiyama (2016) have generalised DSGE models featuring a collateral constraint following Iacoviello (2005) to small open-economies. These papers, however, focus on issues such as quantifying the shocks that are of importance for the housing market (Ng \& Feng 2016)

\footnotetext{
${ }^{30}$ To do this we regress all variables against a constant and a dummy for the inflation-targeting period, rather than demeaning the data, which is akin to allowing the intercept to shift for all equations in the VAR in 1993:Q1. Given that other countries, such as the United Kingdom and Canada, also deflated at around this time and are included in the aggregates we use for the foreign variables, we also allow for breaks in these series. The DSGE parameters obtained are similar to the short sample estimates, and are given in the on-line appendix.

${ }^{31}$ Pagan \& Robinson (2012) examine whether a similar extension of Smets \& Wouters (2007), due to Gilchrist, Ortiz \& Zakrajšek (2009), can forecast recessions (that is, they focus on turning points). They find that "..at best it would seem that the GOZ model would have predicted two of the seven recessions." A key reason demonstrated for this is that the business cycle characteristics of the model are heavily influenced by the contemporaneous innovations to the structural shocks, which cannot, by definition, be forecast. It should be noted that many models find it difficult to forecast recessions (see Harding \& Pagan (2016))
} 
and whether collateral constraints help explain consumption behaviour (Christensen et al. 2016), rather than forecasting. ${ }^{32}$ Kolasa \& Rubaszek (2015) reviews the forecasting performance for the U.S. of both the models with financial frictions in the corporate sector following Bernanke et al. (1999) and collateral constraints for the household sector. ${ }^{33}$ They find that including financial frictions improves the forecasts during times of financial stress, with the collateral constraint model performing particularly well. However, in non-crisis times there is no "uniform improvement", and while pooling the models does improve the forecasts "...the optimal weights on models exhibit a substantial degree of variation over time." (p.2 $)^{34}$

\section{Conclusions}

Reflecting the importance of commodities for the Australian economy, we have extended a baseline smallopen economy DSGE model to include an explicit commodity sector, and studied its forecasting performance and that of a BVAR model using the DSGE as a prior. We found that while the BVAR tends to improve the forecasting performance of the DSGE, for output growth more accurate forecasts could be obtained from simple benchmarks, such as a small open economy Minnesota BVAR. Alternatively, for forecasting inflation it was more competitive, but did not outperform a a Bayesian FAVAR model, which had the benefit of using a much wider range of information than the other models. While the DSGE model could be enriched further, for example by including financial frictions relating to the housing sector, the performance of the FAVAR model suggests that one other potentially fruitful avenue for future research is to study whether incorporating external information, such as conditioning on the nowcasts from external experts, as discussed by Del Negro \& Schorfheide (2013), would improve its ability to forecast the Australian economy.

\footnotetext{
${ }^{32}$ For the Iacoviello \& Neri (2010) model of the U.S., however, Pagan \& Robinson (2012) found a similarly large role for the innovations to the contemporaneous shocks in influencing the characteristics of the business cycle as for the financial accelerator approach, suggesting that the power of models containing collateral constraints for forecasting recessions may also be limited.

${ }^{33}$ Brzoza-Brzezina \& Kolasa (2013) compare the estimated models including either type of financial friction using marginal likelihoods and other methods and conclude that the financial accelerator approach is preferred, although "...even this model does not make a clear improvement of the New Keynesian benchmark...".

${ }^{34}$ Kolasa \& Rubaszek (2015) also consider density forecasts, and find that "...during normal, non-crisis times, ... the average quality of the density forecasts actually deteriorates. (p.2)."
} 


\section{References}

Abbas, S. K., Bhattacharya, P. S., Mallick, D. \& Sgro, P. (2016) The New Keynesian Phillips Curve in a Small Open Economy: Empirical Evidence from Australia, The Economic Record, 92, 409-434.

Atkeson, A. \& Ohanian, L. E. (2001) Are Phillips curves useful for forecasting inflation?, Quarterly Review, $2-11$.

Beechey, M. \& Österholm, P. (2008) A Bayesian Vector Autoregressive Model with Informative Steady-state Priors for the Australian Economy, The Economic Record, 84, 449-465.

Bernanke, B. S., Gertler, M. \& Gilchrist, S. (1999) The Financial Accelerator in a Quantitative Business Cycle Framework, Handbook in Economics 15, Elsevier Science, Amsterdam, 1341-1393.

Brischetto, A. \& Voss, G. (1999) A Structural Vector Autoregression Model of Monetary Policy in Australia, RBA Research Discussion Papers rdp1999-11, Reserve Bank of Australia.

Brzoza-Brzezina, M. \& Kolasa, M. (2013) Bayesian Evaluation of DSGE Models with Financial Frictions, Journal of Money, Credit and Banking, 45, 1451-1476.

Cagliarini, A., Robinson, T. \& Tran, A. (2011) Reconciling Microeconomic and Macroeconomic Estimates of Price Stickiness, Journal of Macroeconomics, 33, 102-120.

Casella, G. (1985) An Introduction to Empirical Bayes Analysis, The American Statistician, 39, 83-87.

Christensen, I., Corrigan, P., Mendicino, C. \& Nishiyama, S.-I. (2016) Consumption, housing collateral and the Canadian business cycle, Canadian Journal of Economics, 49, 207-236.

Christiano, L. J., Trabandt, M. \& Walentin, K. (2011) Introducing financial frictions and unemployment into a small open economy model, Journal of Economic Dynamics and Control, 35, 1999-2041.

Clemen, R. T. (1989) Combining Forecasts: A Review and Annotated Bibliography, International Journal of Forecasting, 5, 559-583.

DeJong, D. N., Ingram, B. \& Whiteman, C. (1993) Analyzing VARs with Monetary Business Cycle Model Priors, in Proceedings of the American Statistical Association, Bayesian Statistics Section, American Statistical Association, Alexandria, 160-169.

Del Negro, M., Hasegawa, R. B. \& Schorfheide, F. (2016) Dynamic prediction pools: An investigation of financial frictions and forecasting performance, Journal of Econometrics, 192, 391-405.

Del Negro, M. \& Schorfheide, F. (2004) Priors from General Equilibrium Models for VARS, International Economic Review, 45, 643-673.

Del Negro, M. \& Schorfheide, F. (2013) DSGE Model-Based Forecasting, in G. Elliott \& A. Timmermann, eds., Hanbook of Economic Forecasting, volume 2, Elsevier, 57-140.

Dib, A. (2008) Welfare Effects of Commodity Price and Exchange Rate Volatilities in a Multi-Sector Small Open Economy Model, Working Paper 2008-8, Bank of Canada.

Diebold, F. X. \& Mariano, R. S. (1995) Comparing Predictive Accuracy, Journal of Business Es Economic Statistics, 13, 253-263.

Dungey, M., Fry-McKibbin, R. \& Linehan, V. (2014) Chinese resource demand and the natural resource supplier, Applied Economics, 46, 167-178.

Dungey, M. \& Pagan, A. (2000) A Structural VAR Model of the Australian Economy, The Economic Record, 76, 321-342.

Dungey, M. \& Pagan, A. (2009) Revisiting a SVAR Model of the Australian Economy, Economic Record, 85, $1-20$.

Edge, R. M. \& Gürkaynak, R. S. (2010) How Useful are Estimated DSGE Model Forecasts for Central Bankers?, Brookings Papers on Economic Activity, Fall, 209-244. 
Eslake, S. (2011) Productivity: The Lost Decade, in J. Kearns \& H. Gerard, eds., The Australian Economy in the 2000s, Proceedings of a Conference, Reserve Bank of Australia, Sydney, 223-254.

Galí, J. \& Gertler, M. (1999) Inflation Dynamics: A Structural Econometric Analysis, Journal of Monetary Economics, 44, 195-222.

Galí, J. \& Monacelli, T. (2005) Monetary Policy and Exchange Rate Volatility in a Small Open Economy, Review of Economic Studies, 72, 707-734.

Gerard, H. \& Nimark, K. (2008) Combining Multivariate Density Forecasts Using Predictive Criteria, Research Discussion Paper 2008-02, RBA.

Ghent, A. C. (2009) Comparing DSGE-VAR forecasting models: How big are the differences?, Journal of Economic Dynamics and Control, 33, 864-882.

Giacomini, R. \& White, H. (2006) Tests of Conditional Predictive Ability, Econometrica, 74, 1545-1578.

Gilchrist, S., Ortiz, A. \& Zakrajšek, E. (2009) Credit Risk and the Macroeconomy: Evidence from an Estimated DSGE Model, Presented to 2009 RBA Economic Research Workshop: Monetary Policy in Open Economies.

Gillitzer, C. \& Kearns, J. (2007) Forecasting with Factors: The Accuracy of Timeliness, Research Discussion Paper 2007-03, Reserve Bank of Australia.

Harding, D. \& Pagan, A. (2016) The Econometric Analysis of Recurrent Events in Macroeconomics and Finance, number 10744 in Economics Books, Princeton University Press, ISBN 0x60a788d8.

Hodge, A., Robinson, T. \& Stuart, R. (2008) A Small BVAR-DSGE Model for Forecasting the Australian Economy, Research Discussion Paper 2008-04, RBA.

Iacoviello, M. (2005) House Prices, Borrowing Constraints, and Monetary Policy in the Business Cycle, The American Economic Review, 95(3), 739-764.

Iacoviello, M. \& Neri, S. (2010) Housing Market Spillovers: Evidence from an Estimated DSGE Model, American Economic Journal: Macroeconomics, 2(2), 125-164.

Jääskelä, J. P. \& Nimark, K. (2011) A Medium-Scale New Keynesian Open Economy Model of Australia, Economic Record, 87, 11-36.

Jiang, B., Athanasopoulos, G., Hyndman, R. J., Panagiotelis, A. \& Vahid, F. (2017) Macroeconomic forecasting for Australia using a large number of predictors, Monash Econometrics and Business Statistics Working Papers 2/17, Monash University, Department of Econometrics and Business Statistics.

Justiniano, A. \& Preston, B. (2010) Monetary Policy and Uncertainty in an Empirical Small Open-Economy Model, Journal of Applied Econometrics, 25, 93-128.

Kadiyala, K. R. \& Karlsson, S. (1997) Numerical Methods for Estimation and Inference in Bayesian VARModels, Journal of Applied Econometrics, 12, 99-132.

Kearns, J. \& Lowe, P. (2011) Australia's Prosperous 2000s: Housing and the Mining Boom, in J. Kearns \& H. Gerard, eds., The Australian Economy in the 2000s, Proceedings of a Conference, Reserve Bank of Australia, Sydney, 73-100.

Kim, S. \& Roubini, N. (2000) Exchange rate anomalies in the industrial countries: A solution with a structural VAR approach, Journal of Monetary Economics, 45, 561-586.

Knop, S. J. \& Vespignani, J. L. (2014) The sectorial impact of commodity price shocks in Australia, Economic Modelling, 42, 257-271.

Kolasa, M. \& Rubaszek, M. (2015) Forecasting using DSGE models with financial frictions, International Journal of Forecasting, 31, 1-19.

Kolasa, M., Rubaszek, M. \& Skrzypczyński, P. (2012) Putting the New Keynesian DSGE Model to the Real-Time Forecasting Test, Journal of Money, Credit and Banking, 44, 1301-1324. 
Koop, G. \& Korobilis, D. (2010) Bayesian Multivariate Time Series Methods for Empirical Macroeconomics, Foundations and Trends® in Econometrics, 3, 267-358.

Lees, K., Matheson, T. \& Smith, C. (2011) Open Economy Forecasting with a DSGE-VAR: Head to Head with the RBNZ Published Forecasts, International Journal of Forecasting, 27, 512-528.

Litterman, R. B. (1986) Forecasting with Bayesian Vector Autoregressions-Five Years of Experience, Journal of Business \& Economic Statistics, 4, 25-38.

Lubik, T. A. \& Schorfheide, F. (2007) Do Central Banks Respond to Exchange Rate Movements? A Structural Investigation, Journal of Monetary Economics, 54, 1069-1087.

Manalo, J., Perera, D. \& Rees, D. M. (2015) Exchange rate movements and the Australian economy, Economic Modelling, 47, 53-62.

Monacelli, T. (2005) Monetary Policy in a Low Pass-Through Environment, Journal of Money, Credit and Banking, 37, 1047-1066.

Ng, E. C. \& Feng, N. (2016) Housing market dynamics in a small open economy: Do external and news shocks matter?, Journal of International Money and Finance, 63, 64-88.

Nimark, K. P. (2009) A Structural Model of Australia as a Small Open Economy, Australian Economic Review, 42, 24-41.

Norman, D. \& Richards, A. (2012) The Forecasting Performance of Single Equation Models of Inflation, The Economic Record, 88, 64-78.

Pagan, A. \& Robinson, T. (2012) Assessing the Implications of Financial/Real Interactions for Business Cycles in Macroeconometric Models, University of Southern California Dornsife College, Center for Applied Financial Economics Working Paper, available at <http://dornsife.usc.edu/assets/sites/462/docs/papers/working/finstressrev2c.pdf $>$.

Rees, D. M., Smith, P. \& Hall, J. (2016) A Multi-sector Model of the Australian Economy, The Economic Record, 92, 374-408.

Robinson, T. (2013) Estimating and Identifying Empirical BVAR-DSGE Models for Small Open Economies, Research Discussion Paper 2013-06, RBA.

Smets, F. \& Wouters, R. (2007) Shocks and Frictions in US Business Cycles: A Bayesian DSGE Approach, The American Economic Review, 97, 586-606.

Stock, J. H. \& Watson, M. W. (2002) Macroeconomic Forecasting Using Diffusion Indexes, Journal of Business \&. Economic Statistics, 20, 147-162.

Summers, P. M. (2001) Forecasting Australia's economic performance during the Asian crisis, International Journal of Forecasting, 17, 499-515.

Trevor, R. G. \& Thorp, S. J. (1988) VAR Forecasting Models of the Australian Economy: A Preliminary Analysis, Australian Economic Papers, 27, 108-120.

Tsiaplias, S. \& Chua, C. L. (2010) Forecasting Australian Macroeconomic Variables Using A Large Dataset, Australian Economic Papers, 49, 44-59.

Vespignani, J. L. (2013) The Industrial Impact of Monetary Shocks During the Inflation-Targeting Era in A ustralia, Australian Economic History Review, 53, 47-71.

Villani, M. (2009) Steady-state priors for vector autoregressions, Journal of Applied Econometrics, 24, 630650 .

Voss, G. \& Willard, L. (2009) Monetary policy and the exchange rate: Evidence from a two-country model, Journal of Macroeconomics, 31, 708-720.

Wozniak, T. (2016) Bayesian Vector Autoregressions, Australian Economic Review, 49, 365-380. 